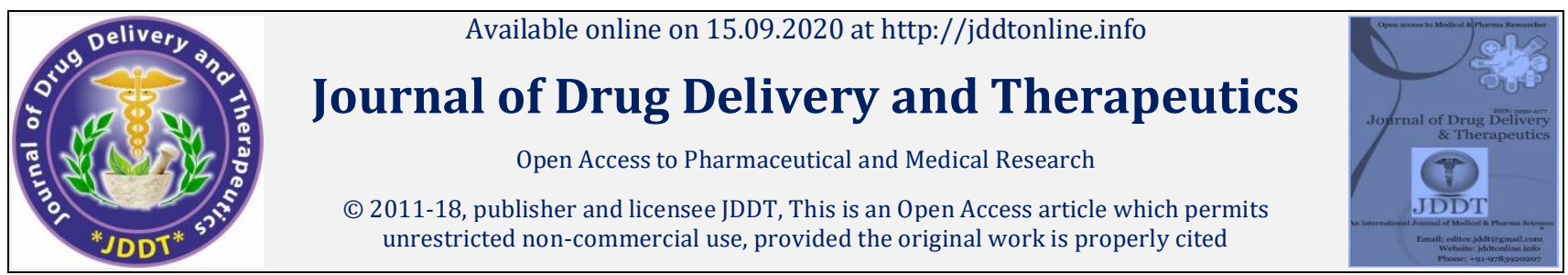

Open 2 Access

Research Article

\title{
Chemical investigation, the antibacterial and antifungal activity of different parts of Capparis spinosa extracts
}

\author{
Nadia Benzidane ${ }^{1}$, Ridha Aichour ${ }^{1}$, Sofiane Guettaf ${ }^{2 *}$, Noureddine Laadel ${ }^{3}$, Seddik Khennouf ${ }^{4}$, \\ Abderrahmane Baghiani ${ }^{1}$ and Lekhmici Arrar ${ }^{1}$ \\ ${ }^{1}$ Laboratory of Applied Biochemistry, Faculty of Nature and Life Sciences, University Ferhat Abbas Sétif-1, Algeria \\ 2 Laboratory of Applied Microbiology, Faculty of Nature and Life Sciences, University Ferhat Abbas Sétif-1, Algeria \\ ${ }^{3}$ Laboratory of Improvement and Development of Plant and Animal Production, Faculty of Nature and Life Sciences, University Ferhat Abbas \\ Sétif-1, Algeria \\ ${ }^{4}$ Laboratory of Phytotherapy applied to chronic diseases, Faculty of Nature and Life Science, University Ferhat Ab bas Sétif-1, Algeria
}

\begin{abstract}
Capparis spinosa (Capparidacea), is one of the most used medicinal plants worldwide. It is used for the treatment of various diseases because of its biological and pharmacological effect, such as antioxidant, anticancer, antihypertensive, antidiabetic and antibacterial. Phytochemical analysis of the plant showed that it is a rich source of bioactive constituents, including alkaloids, glucosinolates, tocopherols, carotenoids and polyphenols, which have led to $C$. spinosa being considered as a promising medicinal plant. Our study aims to detail the chemical profiles of the present bioactive responsible for the pharmacological effects of $C$. spinosa; it also aims to experimentally demonstrate the presence of polyphenols in different parts of the plant as well as their antimicrobial effects. For this, we used methanolic and aqueous extracts of the different parts of the plant picked in Beni Aziz in the Sétif region (North-east of Algeria). The extracts subjected to TLC and HPLC showed that they were rich in flavonoids and phenolic acids. This led to find that rutin was the most dominant compound in most of our extracts. On the other hand, the antimicrobial effect was tested by the disk diffusion method on three bacterial strains: E. coli, P. aeruginosa and S. aureus and two fungi: C. albicans and A. flavus. Candida albicans's antifungal effect of our extracts was absent. While the same extracts showed a slight inhibitory activity against Aspergillus flavus. As for the antibacterial effect, it exists only for the methanolic extract of the twigs against Staphylococcus aureus. While the other extracts only showed a slight inhibitory activity against the same strain. The other strains of bacteria were resistant to all extracts at any used concentration.
\end{abstract}

Keywords: Capparis spinosa, Pharmacological effect, Chemical investigation, antibacterial activity, phenolic compounds, antifungal activity.

Article Info: Received 11 July 2020; Review Completed 22 Aug 2020; Accepted 27 August 2020; Available online 15 September 2020

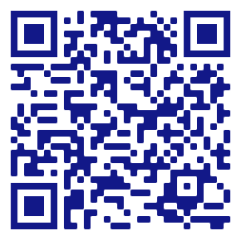

\section{Cite this article as:}

Benzidane N, Aichour R, Guettaf S, Laadel N, Khennouf S, Baghiani A, Arrar L, Chemical investigation, the antibacterial and antifungal activity of different parts of Capparis spinosa extracts, Journal of Drug Delivery and Therapeutics. 2020; 10(5):118-125 http://dx.doi.org/10.22270/jddt.v10i5.4388

*Address for Correspondence:

Sofiane Guettaf, Laboratory of Applied Microbiology, Faculty of Nature and Life Sciences, University Ferhat Abbas Sétif-1, Algeria

\section{INTRODUCTION}

Caper (Capparis spinosa L.) belongs to the Capparaceae family native to the Mediterranean region. C. spinosa is one of the most widespread aromatic plants that grows everywhere, on slopes, rocky and stony and generally well adapted to the basin of the dry zones. The wild species of Capparis are found in the surrounding Mediterranean countries extending as far as the great desert in North Africa and in the dry regions of western and central Asia. In the Mediterranean coast, the caper tree can grow wildly only in the Algerian coast. Where it prefers light, well-draining soils with a neutral to alkaline $\mathrm{pH}$. It can also be found in light, sandy or loamy soils $(\mathrm{pH}=7.5-8) .{ }^{1}$ The harvest's perfect time of caper in Algeria is June, and it is mainly used for traditional remedies. 2 Plants are a valuable source of a wide range of secondary metabolites, which are used as pharmaceuticals, agrochemicals, flavors, fragrances, colors, biopesticides ${ }^{3}$ and food additives. As a result of accumulated experience from the previous generations, today, all the world's cultures have an extensive knowledge of herbal medicine. Capparis spinosa which was commonly used as medicinal plant, contains many biologically active chemical groups including, alkaloids, glycosides, tannins, phenolics, flavonoids, triterpenoids steroids, carbohydrates, saponins and a wide range of minerals and elemental electrolytes. It exerted many pharmacological effects including antimicrobial $\mathbf{4}$, cytotoxic, antidiabetic 5, 6, anti-inflammatory 
7, antioxidant 8, 9, 10, cardiovascular, bronchorelaxant 11, antihepatotoxic, 12, antiproliferative agent 13, Moreover, nbutanol extract of $C$. spinosa inhibits the growth of tumor cells, ${ }^{14}$. It has anti-hyperglycemic and anti-obesity effects, $\mathbf{5}$. Also, its aqueous extract reduced cholesterol, triglycerides and glucose in normal and severe hyperglycemic rats, [15]16. Clinical studies have shown that the caper extract has antiarthritic effect 17, 18. Phytochemical studies have reported that the extract of $C$. spinosa contains antioxidant compounds such as flavonoids, quercetin and kaempferol glycosides. 19 and many other effects.

\section{Common names}

Capparis spinosa L, (Capparidaceae) commonly known as the El-Kabbar caper plant in Algeria.

Arabic: Kabbar, Assef; Berber: Taylulut, Tailoulout, Amserlih, Ouailoulou; English: Caper Bush, Caperbush, Caper, Caperberry; French: Câprier, Caprier commun, Câpres, Fabagelle, Tapana, German: Kapper, Kapernstrauch; Italian: Cappero, Capperone (fruit); Spanish: Alcaparra, Caparra, Tapana; Alcaparron, Caperberries; Swedish: Kapris; Telugu: Kokilakshmu; Urdu: Kabar Family: Capparidaceae.20

Botanical status: The botanical status of Capparis spinosa $\mathrm{L}$ is given in Table 1.

\section{MATERIALS AND METHODS}

\section{Plant material}

Capparis spinosa has been collected from the region of Beni Aziz (Sétif region) North-east of Algeria and identified by $\mathrm{Pr}$ H. Laouer, from Sétif 1 University, Algeria. A voucher specimen has been preserved in the laboratory. Leaves, seeds and capers (fruits) of $C$. spinosa have been dried in the shadow and powdered before the extraction. (Figure 1)

\section{Preparation of Capparis spinosa extracts}

To obtain the aqueous extracts, $10 \mathrm{~g}$ of the powder of each of the different plant parts (roots, leaves, flowers, seeds and fruits) we have mixed with $100 \mathrm{~mL}$ of distilled water, heated for $15 \mathrm{~min}$, and stirred 24 hours in the darkness at $4^{\circ} \mathrm{C}$. We have filtered the aqueous extract through a glass with cotton to remove particles. The filtrate has been lyophilized and stored at $-20^{\circ} \mathrm{C}$ until to use. 10

We have put the dried plant material in a blender and subsequently mixed with a $10-20$ volumes of $85 \%$ aqueous methanol. The slurry has been placed at room temperature for one week and we filtered the extract through a Buchner funnel. The methanol has been removed by rotary evaporation. 21, 22

Table 1: Botanical situation of the Capparis species

\begin{tabular}{|l|l|}
\hline Reign & Vegetal \\
\hline kingdom & Plantae \\
\hline sub- kingdom & Tracheobionta \\
\hline phylum & Magnoliophyta \\
\hline Class & Magnoliopsida \\
\hline Sub-class & Dilleniidae \\
\hline Order & Capparales \\
\hline Family & Capparaceae \\
\hline Species & Capparis spinosa \\
\hline
\end{tabular}

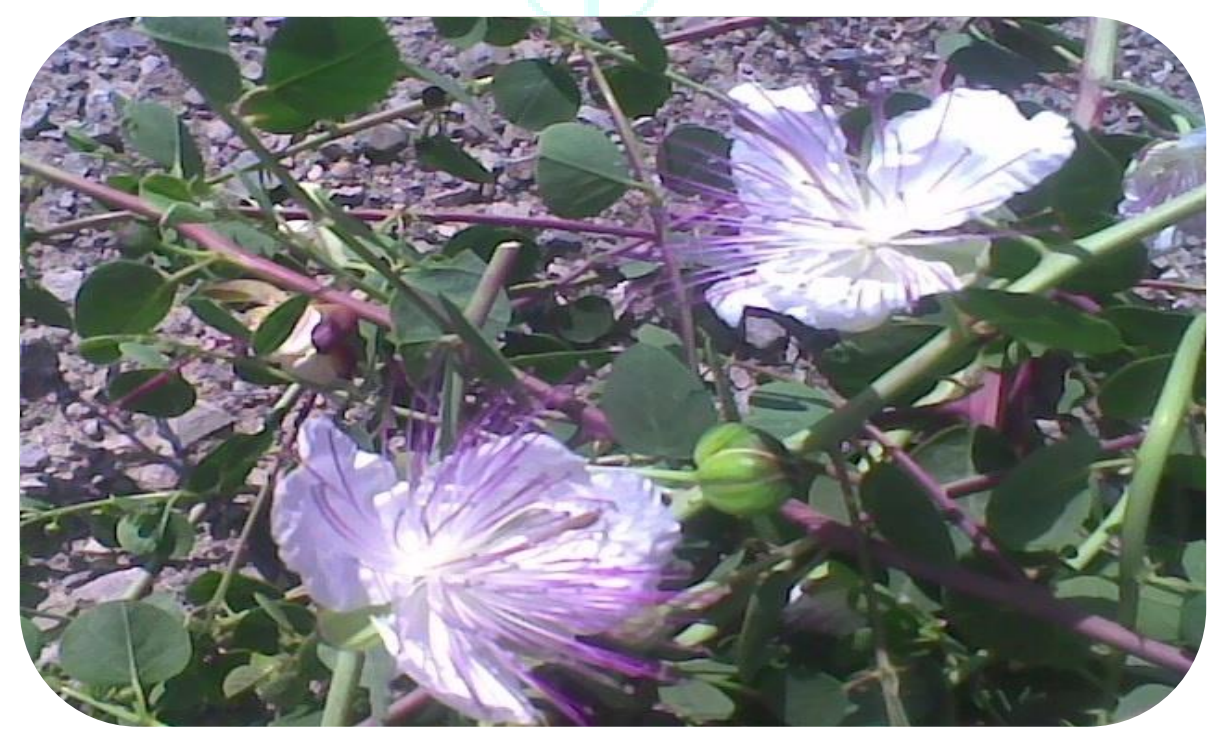

Figure 1: Capparis spinosa (flowers, capers, stem leaves).

\section{TLC thin layer chromatography}

The support used in this study is a silica gel plate: $(20 \times$ $20 \mathrm{~cm}, 60 \mathrm{~F} 254)$. The migration system used is: dichloromethane / methanol (86/14) (V / V) for the aqueous and methanolic extracts is $\left(\mathrm{H}_{2} \mathrm{O}, \mathrm{MeOH}\right)$. Four phenolic compounds were also applied to the plate as standards: three flavonoids: Quercetin, (Quer), Rutin, (Rut), and Catechin (Cat), and a phenolic acid: Gallic Acids (AGal) (2mg of each standard in $1 \mathrm{ml}$ of methanol).

Before analyzing aqueous and organic samples, we have applied them in a small spot in the form of $5 \mu \mathrm{l}$ points by a micropipette $1 \mathrm{~cm}$ from the end of the silica gel plate. (the organic sample consisting of $10 \mathrm{mg}$ of the caper extract, seeds, leaves, roots, flowers, twigs and root bark, all are dissolved in $1 \mathrm{ml}$ of methanol, the aqueous sample consists of $10 \mathrm{mg}$ of the different aqueous extracts of capers, seeds, leaves, roots and flowers dissolved in $1 \mathrm{ml}$ of distilled water).

Once it has been impregnated with the different extracts, the plate constituting of the stationary phase is then dried and deposited vertically inside the chromatographic tank where it is traversed by a mobile phase (Dichloromethane / 
Methanol) (80/20) ( $\mathrm{v} / \mathrm{v})$. The flow between the two phases causes migration and separation of the different compounds. After the development of the chromatogram (approximately 20 minutes); the plates have been further dried and examined under a UV lamp $(\lambda=254 \mathrm{~nm})$. Our chromatographic tank containing the mobile phase has been saturated beforehand for a period of one hour to allow good elution. Each migrating substance is characterized by its frontal ratio (RF), and its fluorescence after revelation by iodine.

\section{Analysis method by high performance liquid chromatography (HPLC)}

High performance liquid chromatography (HPLC) analysis is arguably the most useful analytical technique for the characterization of phenolic compounds 23 because it exhibits high resolution, high reproducibility, and long life. Relatively short analysis. For the analysis of polyphenols, HPLC: Agilent 1100 colonne C18 monomeric columns with polar grouping are preferable because they allow better selectivity. The wavelength range of flavonols, flavones and isoflavones ranges are from 254-280 $\mathrm{nm}$. The maximum absorption is detected at $270 \mathrm{~nm}$. The organic samples consist $10 \mathrm{mg}$ of the extract of (Capers, Seeds, Leaves, Roots, Flowers, Twigs and Root Bark) each dissolved in $1 \mathrm{ml}$ of methanol, the aqueous sample consists $10 \mathrm{mg}$ of different aqueous extracts of (Capers, Seeds, Leaves, Roots and Flowers) dissolved in $1 \mathrm{ml}$ of distilled water. The six standards: Quercetin, (Quer), Rutin, (Rut), Catechin (Cat), Gallic acid (A Gal), Ferulic acid (AFer) and Tannic acid (AT) are dissolved at a rate of $2 \mathrm{mg}$ in $1 \mathrm{ml}$ of methanol. $5 \mu \mathrm{l}$ of each extract were injected in a C18 column of dimension $(250 \times 4.6 \mathrm{~mm})$ and a particle diameter equal to $5 \mu \mathrm{m}$. The elution solvent consists two phases: - Phase A: (water / Formic acid) (v / v) (99.9 / 0.1) • Phase B: Pure acetonitrile (HPLC gradient). The elution method applied is of the gradient type spread over 60 minutes with a flow rate of $1 \mathrm{ml}$ / min as follows: - from 0 to $10 \mathrm{~min}: 5$ - 25\% B, - from 10 to 25 min: 25 - 40\% B - from 25 to 35 min: $40-60 \%$ B - 35 to $45 \mathrm{~min}$ : $60-80 \% \mathrm{~B}$ - from 45 to $60 \mathrm{~min}: 80 \% \mathrm{~B}$. The detection is done by a UV-Visible detector at a wavelength of $270 \mathrm{~nm}$.

\section{Antimicrobial susceptibility test Bacteria and Fungi strains}

The antibacterial tests were carried out using reference strains: Staphylococcus aureus (ATCC 25923), Escherichia coli (ATCC 25922) and clinical origins strains: Pseudomonas aeroginosa, Aspergillus flavus and Candida albicans obtained from the Laboratory of Bacteriology at Sétif hospital.

\section{Antibacterial activity}

The evaluation of antimicrobial activity has been performed by the agar disc diffusion method cited by 24 . The aqueous extracts are dissolved in water with the dosages: $1 \mathrm{~g} / \mathrm{ml}, 500$ $\mathrm{mg} / \mathrm{ml}, 250 \mathrm{mg} / \mathrm{ml}$ and $125 \mathrm{mg} / \mathrm{ml}$. The methanolic extracts have been dissolved in dimethyl sulfoxide (DMSO) with: 500 $\mathrm{mg} / \mathrm{ml}, 250 \mathrm{mg} / \mathrm{ml}, 125 \mathrm{mg} / \mathrm{ml}$ and $62.5 \mathrm{mg} / \mathrm{ml}$. The bacterial strains are subcultured by the streak method, then incubation at $37^{\circ} \mathrm{C}$ for 18 to $24 \mathrm{~h}$ in order to obtain a young culture and isolated colonies. A colony well isolated has been mixed with $5 \mathrm{ml}$ of sterile distilled water in a test tube in order to have an initial cell density or a turbidity close to 0.5 Mc Farland (Abs: 0.08-0.1 at $625 \mathrm{~nm}$ ). Inoculation is carried out by using a swab dipped in the inoculum, and spread over the entire surface of the Mueller-Hinton agar. The operation is repeated two more times by turning the box $60^{\circ}$ each time to ensure a homogeneous distribution of the inoculum.
Finally, the swab is passed around the edge of the agar surface. Then $6 \mathrm{~mm}$ diameters of Whatman filter paper No3 discs were prepared and impregnated with $30 \mu \mathrm{l}$ of the different concentrations of extracts of Capparis spinosa. The impregnated discs are then gently deposited by sterile forceps on the surface of the inoculated agar. A disk impregnated with DMSO / distilled water is also deposited as a negative control, as well as a ready-to-use disk of Gentamicin (10 mg) serving as a positive control. The petri dishes are incubated in an oven at $37^{\circ} \mathrm{C}$ between 18 and 24 hours. The diameter of inhibition zone has been measured by transparent ruler to nearest $\mathrm{mm}$. Inhibition zone with diameter was less than $12 \mathrm{~mm}$. were considered as having no antibacterial activity, diameter between 12 and $16 \mathrm{~mm}$. were considered moderately active, and these with $>16 \mathrm{~mm}$. were considered highly active. 24

\section{Antifungal activity}

Antifungal susceptibility test in vitro has been tested against pathogenic human fungi Candida albicans and Aspergillus flavus. We used Sabouraud dextrose medium containing chloramphenicol for the fungal suspension from three to five days old, it was made in sterile distilled water and its turbidity was adjusted to $0,5 \mathrm{Mc}$ Farland $\left(10^{7} \mathrm{CFU} / \mathrm{ml}\right)$. An aliquot of $0.1 \mathrm{ml}$ of this fungal suspension was spread over the surface of agar plate. The disc technique was used for the antifungal activity; sterile paper discs of $6 \mathrm{~mm}$ diameter impregnated with $30 \mu \mathrm{l}$ of plant extract. The same procedure was used as described previously. The discs impregnated with DMSO and Fluconale $10 \mathrm{mg} / \mathrm{ml}$ are respectively used as negative and positive controls. ${ }^{25}$

Statistical analysis All determinations were conducted in triplicate and all the results were calculated as mean \pm standard deviation (SD). Statistical analysis was performed using Student's $t$ test for significance. Differences were considered significant at $\mathrm{p} \leq 0.05$.

\section{RESULTS AND DISCUSSION}

\section{Thin Layer Chromatography (TLC)}

The thin layer chromatograms of Capparis spinosa made it possible to separate some substances which were visualized as visible spots (UV $254 \mathrm{~nm}$ ). Each component is characterized by its frontal report.

The extracts with many spots are the richest in polyphenols and flavonoids. Caper extracts: aqueous (4 compounds) and methanolic (5 compounds). Leaf extracts: aqueous (3 compounds) and methanolic (4 compounds). The other extracts have fewer compounds than these last two with: 2 apparent compounds for each of the extracts: aqueous and methanolic from flowers, methanolic from seeds and methanolic from the root bark. 1 single apparent compound for: the aqueous and methanolic extract of the root, the aqueous extract of the seed and the methanolic extract of the twigs. (Figure 2)

Calculation of Front-End Reports $\left(\mathrm{R}_{\mathrm{f}}\right)$ it is the ratio of the distance traveled by the solute $(\mathrm{X}) /$ the distance traveled by the solvent. (Y) $\quad R f=\frac{X}{Y}$ with $\mathrm{Y}=6,6 \mathrm{~cm}$

Table 2: Calculation of the frontal ratios of the standards.

\begin{tabular}{|c|c|c|}
\hline Standards & $\mathbf{X}$ & $\mathbf{R}_{\mathbf{f}}$ \\
\hline Quercetin & 5.2 & 0.78 \\
\hline Rutin & 2 & 0.3 \\
\hline Catechin & 4.2 & 0.63 \\
\hline Gallic acid & 4.3 & 0.65 \\
\hline
\end{tabular}




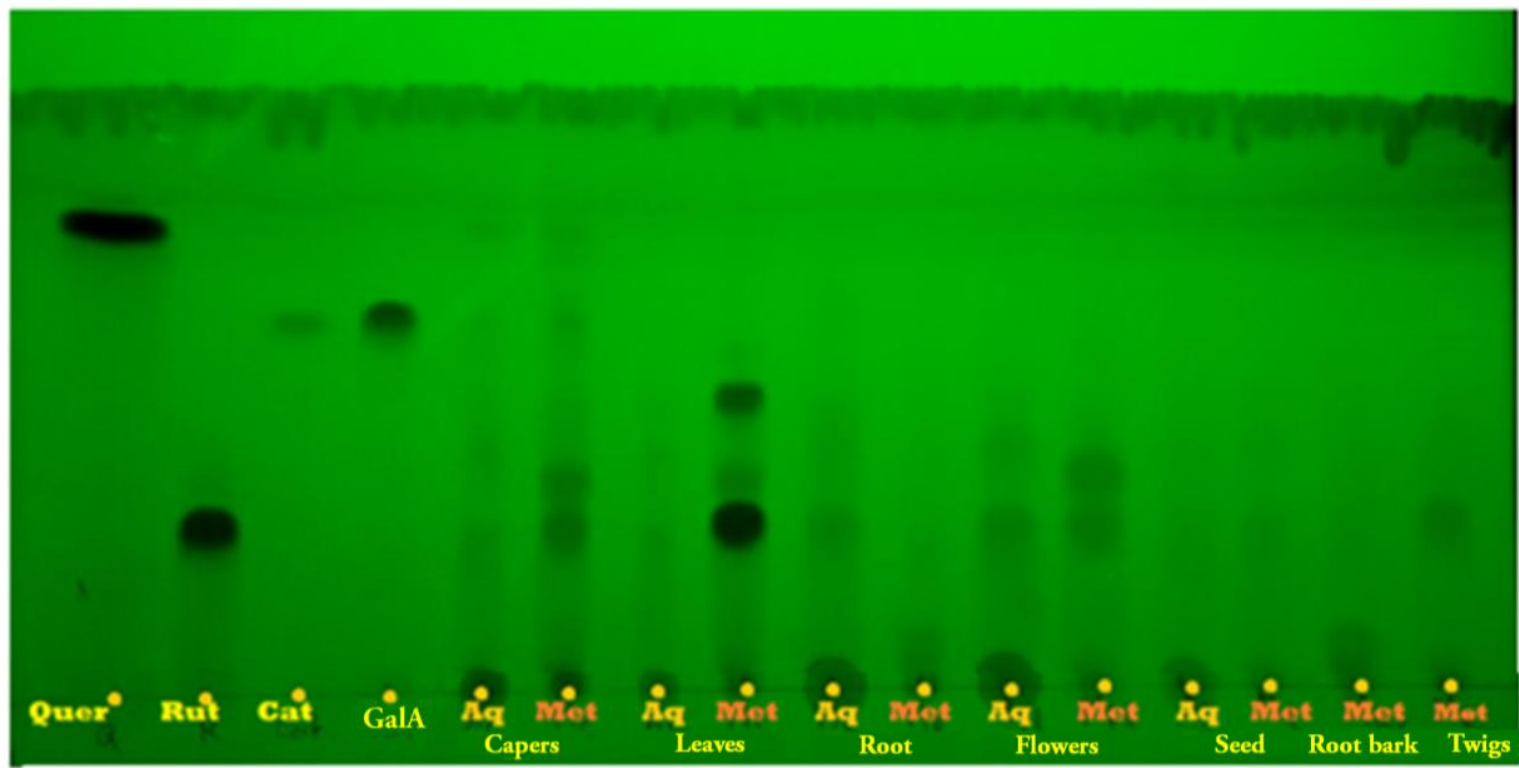

Figure 2: Chromatogram of the aqueous and methanolic extracts of the different parts of Capparis spinosa. (Capers, Leaves, Root, Flowers, Seeds, Root barks and Twigs) and the standards used. (Aq= Aqueous, Met=Methanolic, Quer=Quercetin, Rut= Rutin, Cat= Catechin and GalA= Gallic Acids).

Comparison between the Rf of the different standards (Table 2) and the Rf of the compounds of the plant extracts, we have observed that: Quercetin: present in the aqueous and methanolic extract of caper. Rutin: present in most extracts (the aqueous and methanolic extract of caper, the aqueous and methanolic extract of the leaves; the aqueous and methanolic extract of the flowers; the aqueous extract of the root and the methanolic extract seed, bark and twigs). The rutin was the dominant phenolic in it. [19] This study was designed to assess the phenolic composition, including phenolic acids and in vitro biological activities as antioxidant and mineral analysis of $C$. spinosa $\mathrm{L}$., as well as to evaluate their nutritional and medicinal potentials. Catechin: as with quercetin, it is present in the aqueous and methanolic extract of caper. Gallic Acid: Didn't have any matching spots.

\section{Identification of Phenolic Profile}

In the technique of identifying molecules by HPLC, each compound is characterized by its retention time (TR), which is the time that elapses between the injection of the sample and the appearance of the chromatographic peak. In our qualitative analysis, the use of different standards that marked peaks at different retention times is used to detect the presence that mentioned before in all of our extracts. (Table3)

Table 3: Standard retention time:

\begin{tabular}{|c|c|c|c|c|c|c|}
\hline Standard & Gallic acid & Ferulic acid & Catechin & Rutin & Quercetin & Tannic acid \\
\hline Retention time (min) & 6.1 & 10.35 & 10.49 & 13.22 & 22.37 & Non detectable \\
\hline
\end{tabular}

Note that the tannic acid chromatogram cannot be interpreted, due to its belonging to a very heterogeneous subfamily of polyphenols, we talk here about a tannin bump. 26 The comparison between the retention times of the standards (Figure 3) with those recorded in the chromatograms of the various methanolic and aqueous extracts allowed the probable identification of certain flavonoids and phenolic acids in the different parts of the $C$. spinosa plant, summarized in the table 4 below. follows:

Table 4: Polyphenol contents of different parts of Capparis spinosa.

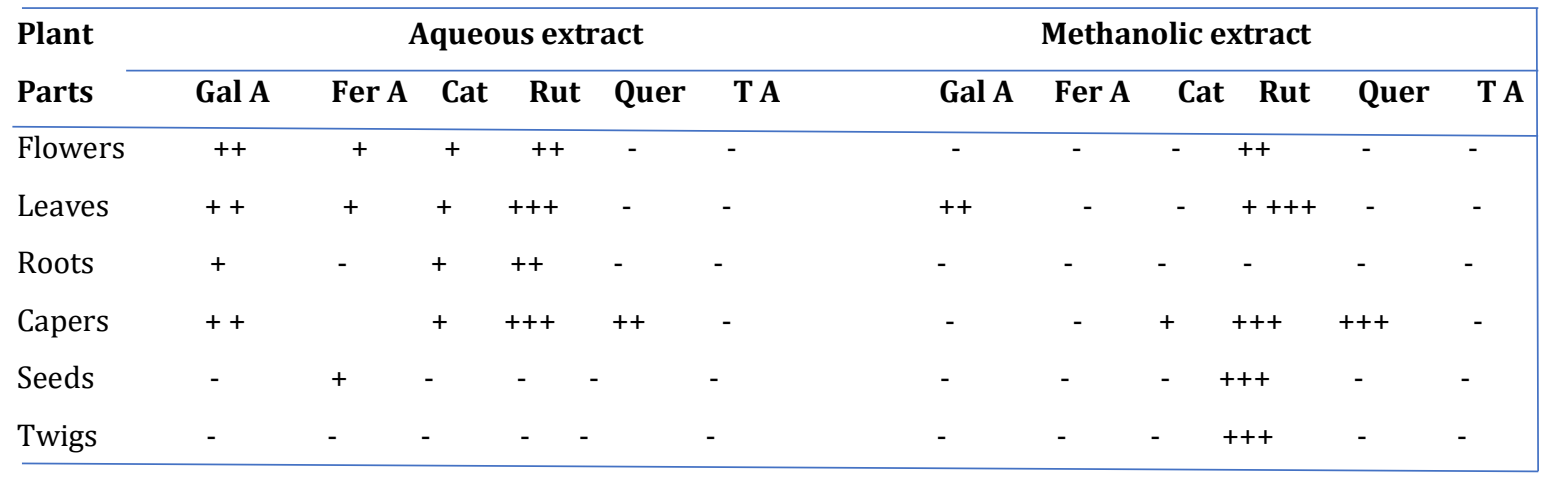


This result joins to the TLC to confirm that rutin is the most abundant flavonoid in the plant, with a presence in most of the extracts. They also confirm the richness of the extracts of capers and leaves, given that they are the parts that have contained the most standard polyphenols. (Table 4) Gallic acid is emerging in HPLC detection as opposed to TLC because it is more sensitive technique with a broad spectrum of detection.

In these results, we find that the methanolic extract is richer in phenolic products compared to other extracts. (Figure 4 and 5)
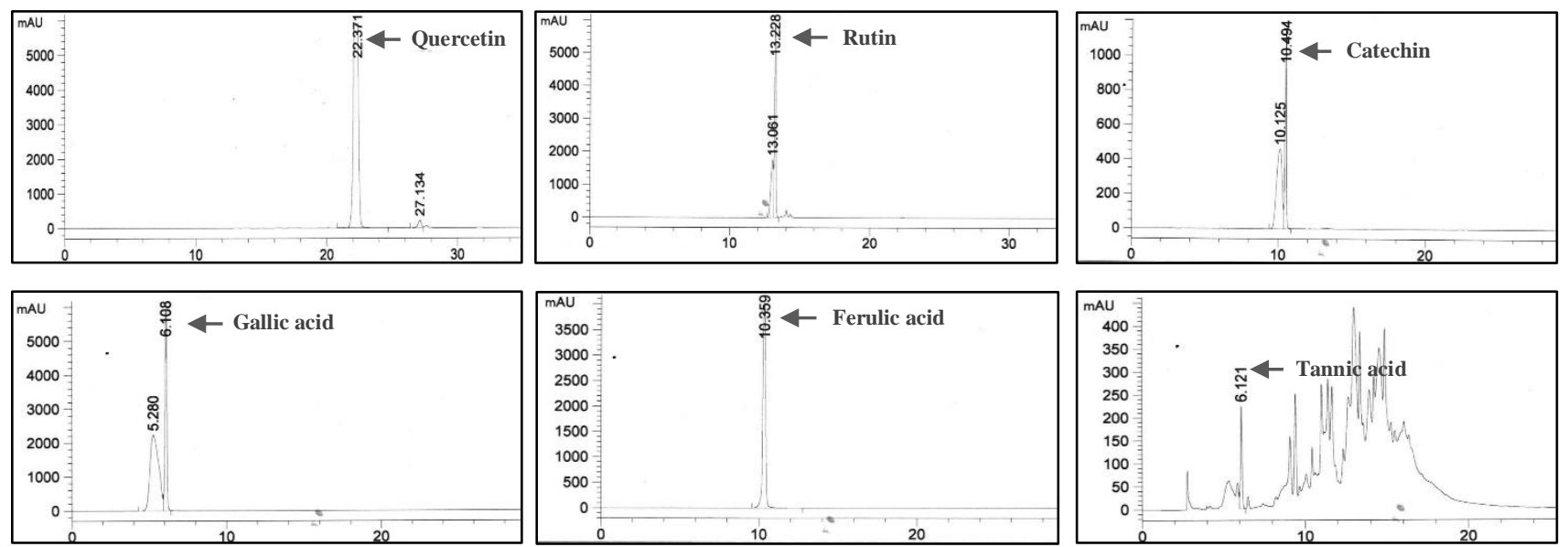

Figure 3: HPLC chromatogram of the different molecules used as standards recorded at $270 \mathrm{~nm}$
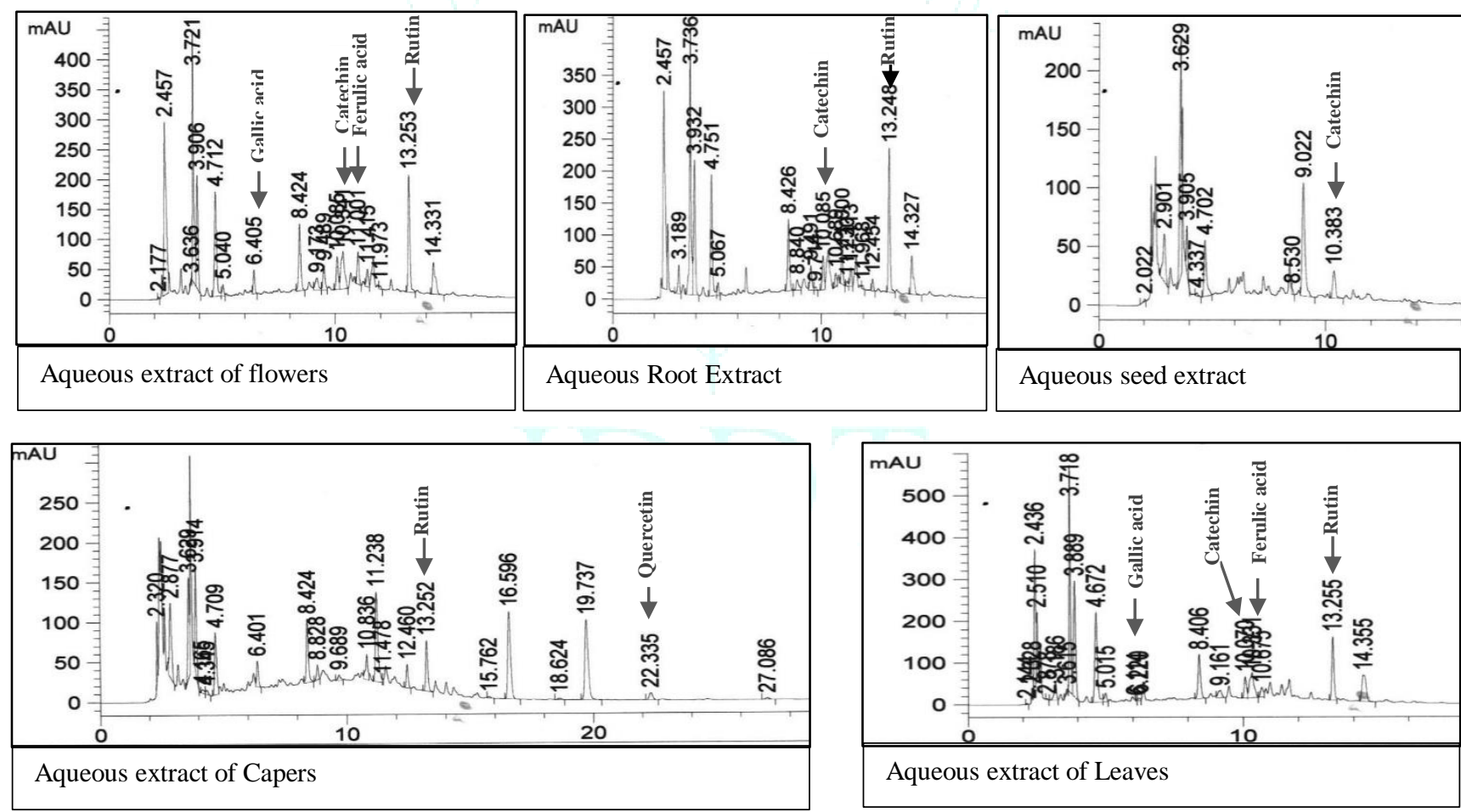

Figure 4: HPLC chromatogram of the various aqueous extracts of Capparis spinosa recorded at $270 \mathrm{~nm}$ 

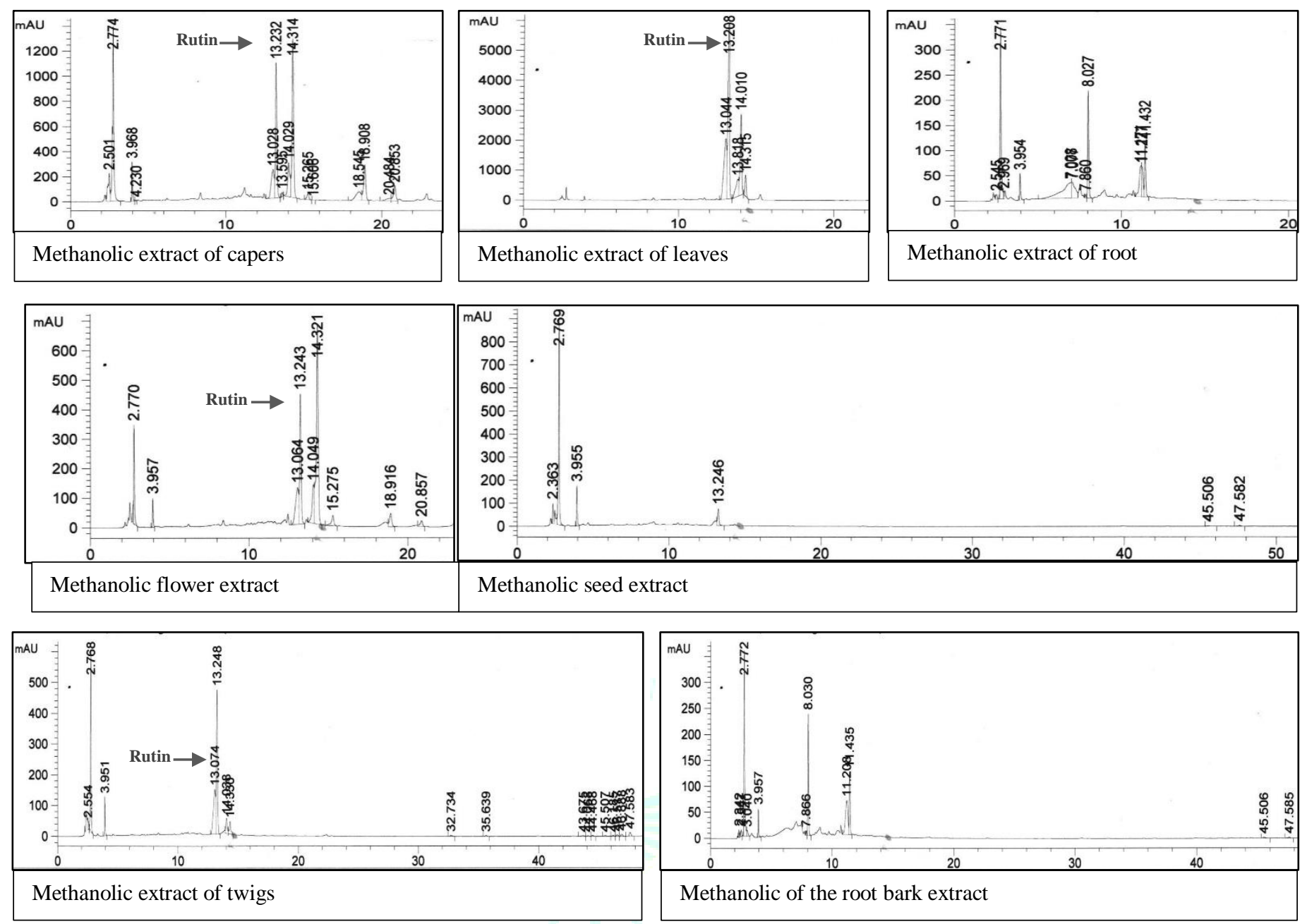

Figure 5: HPLC chromatogram of the different methanolic extracts of Capparis spinosa recorded at $270 \mathrm{~nm}$.

\section{Antibacterial activity}

We have studied the power of extracts from different parts of the plant of $C$. spinosa by the method of diffusion in agar medium by impregnation of the discs by different concentrations, (Mueller-Hinton for the antibacterial test. The antimicrobial activity was estimated by the zone of inhibition around the discs (diameter of inhibition) of the extracts tested on three bacterial strains (Escherichia coli, Pseudomonas aeruginosa and Staphylococcus aureus). All bacterial strains showed sensitivity for the standard antibiotic used (Gentamicin $10 \mathrm{mg}$ ). The inhibitory effects of the growth of germs are manifested by a single extract which is the methanolic extract of the Twigs vis-à-vis $S$. aureus. (Table 5)

Other methanolic extracts of (Flowers, Capers, Leaves and Roots) exhibited dose-dependent areas of inhibition against strains of Staphylococcus aureus. While the aqueous extracts showed no zone of inhibition on all strains regardless of the dose used. The range of the zone of the inhibition was from 11 to $20 \mathrm{~mm}$. Maximum inhibition zone of $25 \mathrm{~mm}$ was obtained with methanolic extract of Capparis spinosa twigs against Staphylococcus aureus. (Table 5)

The aqueous and methanolic extracts did not show any antibacterial effect at all, the doses used either against $\boldsymbol{E}$. Coli or P. aeruginosa. (Table 5)

Our results obtained are in agreement with those of [25] on the same strains, where he found that the ethanolic and aqueous extracts are inactive for E. Coli and P. aeruginosa, while the butanolic extract exhibited an inhibitory effect of bacterial growth for the three strains used.

A research undertaken worked on the leaves of Capparis spinosa, found that the extract is inactive on E. coli, but has suspicious activity on Staphylococcus aureus. ${ }^{27}$

The results obtained for the biological activity (diameter of inhibition (mm)) are collated in tables and the values $1,1 / 2$, $1 / 4$ and $1 / 8$ correspond to the various dilutions of the initial concentration of dry residue of the extract in DMSO which is $1 \mathrm{~g} / \mathrm{ml}$. 
Table 5: Antibacterial activity methanolic extract of different parts of Capparis spinosa.

\begin{tabular}{|c|c|c|c|c|c|c|c|c|c|c|c|c|}
\hline \multirow{3}{*}{$\begin{array}{l}\text { Test Bacteria } \\
\text { Dilution } \\
\end{array}$} & \multicolumn{12}{|c|}{ Inhibition Zone in mm } \\
\hline & \multicolumn{5}{|c|}{ Pseudomonas aeruginosa } & \multicolumn{3}{|c|}{ Staphylococcus aureus } & \multicolumn{4}{|c|}{ Escherichia coli } \\
\hline & 1 & $1 / 2$ & $1 / 4$ & $1 / 8$ & 1 & $1 / 2$ & $1 / 4$ & $1 / 8$ & 1 & $1 / 2$ & $1 / 4$ & $1 / 8$ \\
\hline Twigs & - & - & - & - & $25,12 \pm 0,14$ & $21,15 \pm 0,22$ & $15,17 \pm 0,23$ & $10,23 \pm 1,13$ & - & - & - & - \\
\hline Flowers & - & - & - & - & $20,22 \pm 0,45$ & $15,55 \pm 0,18$ & $10,22 \pm 010$ & $8,75 \pm 0,11$ & - & - & - & - \\
\hline Capers & - & - & - & - & $17,12 \pm 0,22$ & $12,50 \pm 0,40$ & $10,13 \pm 0,03$ & $7,75 \pm 0,10$ & - & - & - & - \\
\hline Leaves & - & - & - & - & $22,02 \pm 0,22$ & $15,50 \pm 1,15$ & $10,13 \pm 0,16$ & $8,78 \pm 0,22$ & - & - & - & - \\
\hline Roots & - & - & - & - & $11,83 \pm 0,29$ & $11,42 \pm 0,63$ & $9,83 \pm 0,2$ & $7,11 \pm 0,11$ & - & - & - & - \\
\hline
\end{tabular}

Values (means \pm SD) are average of three samples of each bacterium, analyzed individually in triplicate. The values $1,1 / 2,1 / 4$ and $1 / 8$ correspond at different dilutions of the initial concentration of the dry residue of the extract in DMSO, which is $1 \mathrm{~g} / \mathrm{ml}$.

\section{Antifungal test}

The extracts used (Flower, Caper, Leaf, and Root) at different concentrations $1 \mathrm{~g} / \mathrm{ml}, 500 \mathrm{mg} / \mathrm{ml}, 250 \mathrm{mg} / \mathrm{ml} 125 \mathrm{mg} / \mathrm{ml}$ prove inactive on two strains used (C. albicans and $\boldsymbol{A}$. flavus) whatever the dose used. Methanolic extracts from twigs showed low activity against Aspergillus flavus. (Table 6)

Table 6: Antifungal activity of methanolic twigs extracts against Aspergillus flavus.

\begin{tabular}{|c|c|c|c|c|c|}
\hline \multirow[t]{2}{*}{ Test Bacteria } & \multicolumn{5}{|c|}{ Inhibition Zone in mm } \\
\hline & Dilution & 1 & $1 / 2$ & $1 / 4$ & $1 / 8$ \\
\hline Aspergillus flavus & & $8,43 \pm 0,38$ & $7,12 \pm 1,44$ & $7,73 \pm 0,29$ & - \\
\hline
\end{tabular}

Values (means \pm SD) are average of three samples of each fungal, analyzed individually in triplicate.

\section{CONCLUSION}

Our attention was focused on Capparis spinosa, which is a Mediterranean plant that is widely used in Algeria, particularly in the region of Sétif, where it was collected for this study.

Many in vivo and in vitro studies are being carried out around the world in order to be able to evaluate the clinical and pharmacological applications of $C$. spinosa with the aim of developing a new natural drug with less toxic and undesirable effects.

Besides that, other studies are done to characterize and quantify the different bioactive molecules present in the plant by using different techniques, such as HPLC and TLC which we used in our study and which have showed that the methanolic and aqueous extracts exhibit are rich source of antioxidant such as flavonoids and phenolic acids with the presence of Rutin and Quercetin in considerably high amounts.

The extracts showed significant effects on bacteria: Staphylococcus aureus. Capparis spinosa L could be used as a potential source of natural antimicrobial agents with beneficial therapeutic effects.

A moderate anti-fungal activity was observed against Aspergillus flavus. Our current research offers the possibility of developing strategies for controlling human pathologies with natural extracts or bioactive metabolites of medicinal plants. Further, phytochemical studies are ongoing to define the chemical structure and characteristics of bioactive compounds especially present in flowers and twigs of this botanical genus.

\section{REFERENCES}

[1] Sauvaigo, E, 1943: Les cultures sur le littoral de la méditerranée ; Provence ; Ligurie ; Algérie. 2ème Edition. Librairie J.-B. Baillère et Fils ; Paris. 197 figures. 456p.

[2] Benseghir-Boukhari L A et Seridi R, 2007 : Le câprier, une espèce arbustive pour le développement rural durable en Algérie : Méditerranée 109.

[3] Mikkelsen MD, Hansen $\mathrm{CH}$, Wittstock U, Halkier BA, Cytochrome P450 CYP79B2 from Arabidopsis catalyzed conversion of triptophane to indole-3,3-acetaldoxime, a precursor of indole glucosinolates and indole-3 acetic acid. J. Biol. Chem. 2000; 275:33712-33717

[4] Boga C, Forlani L, Calienni R. On the antibacterial activity of roots of Capparis spinosa L. Nat Prod Res, 2011; 4:417-21.

[5] Lemhadri A, Eddouks M, Sulpice T and Burcelin R, Antihyperglycaemic and Anti-obesity Effects of Capparis spinosa and Chamaemelum nobile Aqueous Extracts in HFD Mice: American Journal of Pharmacology and Toxicology; 2007; 2(3):106-110

[6] Eddouks M, Lemhadri A, Hebi M, Ahmed EL H, Zeggwagh NA, Bachir EL B, Lhoussaine H, Burcelin R, Capparis spinosa L. aqueous extract evokes antidiabetic effect in streptozotocin-induced diabetic mice. Avicenna J Phytomed, 2017; 7(2):191-198.

[7] Aichour R, Charef N, Baghiani A, Arrar L, Immonumodulatory effects of Algerian caper., Int J Pharm Sci, 2016; 8:51-54.

[8] Tlili N, Khaldi A, Triki S, Phenolic compounds and vitamin antioxidants of caper (Capparis spinosa). Plant Foods Human Nutr, 2010; 3:260-5 
[9] Siracusa L, Kulisic-Bilusic T, Politeo O, Phenolic composition and antioxidant activity of aqueous infusions from Capparis spinosa L. and Crithmum maritimum L. before and after submission to a two-step in vitro digestion model. J Agric Food Chem, 2011; 23:12453-9.

[10] Arrar L., Benzidane N., Krache I., Charef N., Khennouf S., Baghiani A, Comparison between polyphenol contents and antioxidant activities of different parts of Capparis spinosa L: Pharmacognosy communication: 2013; 3(2).

Benzidane N., Charef N., Krache I., Baghiani A, Arrar L, In vitro bronchorelaxant effects of Capparis spinosa aqueous extracts on rat trachea: Journal of applied pharmaceutical science: 2013; 3(09):085-088.

[12] Aghel N, Rashidi I, Mombeini A, Hepatoprotective activity of Capparis spinosa root bark against $\mathrm{CCl} 4$ induced hepatic damage in mice. Iranian J Pharm Res, 2007; 4:285-90.

[13] Wu JH, Chang FR, Hayashi KI, Antitumor Agents. Part 218: Cappamensin A, a new in vitro anticancer principle, from C. sikkimensisy. Bioorg Med Chem Lett, 2003; 13:2223-2225.

[14] Yu-Bin J, Lei Y, N-Butanol Extract of Capparis spinosa L. Induces Apoptosis Primarily through a Mitochondrial Pathway Involving mPTP Open, Cytochrome C Release and Caspase Activation. Asian Pac J Cancer Prev, 2014; 15:9153-9157.

[15] Eddouks M, Lemhadri A, Michel J B, Caraway and caper: Potential antihyperglycaemic plants in diabetic rats. J Ethnopharmacol, 2004; 94:143-148.

[16] Eddouks M, Lemhadri A, Michel JB, Hypolipidemic activity of aqueous extract of Capparis spinosa L. in normal and diabetic rats. J Ethnopharmacol, 2005; 98:345-350.

[17] Panico AM, Cardileb T V, Garufia F, Pugliaa C, Bonina F, Ronsisvalle G, Protective effect of Capparis spinosa on chondrocytes Life Sciences, 2005; 77:2479- 2488.

[18] Feng X, Lu J, Xin H, Zhang L, Wang Y, Tang K, Anti-arthritic active fraction of Capparis spinosa L. fruits and its chemical constituents. Yakugaku Zasshi J Pharmaceut Soc Japan, 2011; 131:423-429.

[19] Argentieri M, Macchia F, Papadia P, Fanizzi FP, Avato,
Bioactive compounds from Capparis spinosa subsp. Rupestris. Ind Crop Prod, 2012; 36:65-69.

[20] Jagannath R, Phytochemical and pharmacological screening on roots of $C$. spinosa L: Capparidacea. India: Rajiv Gandhi; University of Health Sciences. 2009.

[21] Ateyyat MA, Al-Mazra'awi M, Abu-Rjai T and Shatnawi MA: Aqueous extracts of some medicinal plants are as toxic as Imidacloprid to the sweet potato whitefly, Bemisia tabaci. Journal of Insect Science. 2009; 9:1-6.

[22] Bouzid W, Yahia M, Abdeddaim M, Aberkane MC and Ayachi A, Evaluation de l'activité antioxydante et antimicrobienne des extraits de l'Aubepine monogyne. Lebanese Science Journal. 2011 ; 12(1):59-69.

[23] Gomez-Caravaca. A.M, Gomez-Romero M, Arraez-Roman D, Segura-Carretero A, Fernandez-Gutierrez A, Advances in the analysis of phenolic compounds in products derived from bees. J pharmaceutical and biomedical Analysis: 2006; 41:1220-1234.

[24] Treki S. A, Merghem R., Dehimat L, Etude Phytochimique et Evaluation de l'Activité Antibactérienne d'une Labié : Thymus hirtus. Sciences \&Technologie. 2009 ; C 29:25-29.

[25] Mahasneh A M, Screening of some indigenous Qatari medicinal plants for antimicrobial activity: phytothera res, 2002; 16:751-753.

[26] Lantoo T A; Dorman H J D; Shikov A N; Pozharitskaya O N; Makarov V G; Tikhonov P V; Hiltunen R et Raasmaja A, Chemical composition, antioxidative activity and cell viability effects of siberian pine extract food chemistry; 2009; 112(4):936-943

[27] Proestos C, Boziaris IS, Nychas G-JE et Komaitis M, Analysis of flavonoid and phenolic acids in greek aromatic plants: investigation of their antioxidant and antimicrobial Activity: Food chemistry: 2006; 95:644-671 